\title{
Article \\ Owen Coggins \\ Distortion, restriction and instability \\ Distortion, restriction and instability: Violence against the self in depressive suicidal black metal
}

\section{Owen Coggins}

The Open University

Owen Coggins researches violence, ambiguity and mysticism in popular music, particularly in relation to extreme music and noise. His monograph, Mysticism, Ritual and Religion in Drone Metal was published by Bloomsbury Academic in 2018, and, in addition to contributing several articles to Metal Music Studies his work has appeared in Popular Music, Implicit Religion, and Diskus: Journal of the British Association for the Study of Religion amongst others. He also runs Oaken Palace Records, a registered charity raising money for endangered species through releasing drone records. $\mathrm{He}$ is Honorary Associate of the Religious Studies Department at the Open University. Contact: Religious Studies Department, The Open University, Walton Hall, Milton Keynes MK7 6AA, UK.

E-mail: owen.coggins@open.ac.uk https://orcid.org/0000-0002-8322-1583

\begin{abstract}
In the underground subgenre of depressive suicidal black metal (DSBM), extremes of violence against the self are presented in combination with a restrictive version of black metal. Album covers feature explicit photographs of self-cutting or drawings of suicide
\end{abstract}


by hanging; vocals are tortured screams expressing extreme suffering, and guitar sounds are so distorted that they begin to approach an ambient atmospheric blur. Given the history of concern about metal and its health implications, I investigate DSBM as a case in which representation of harm in music is overt, explicit and extreme, yet the health impact of the music is undetermined. I discuss how different modalities of distortion and restriction may connect the sound of DSBM to themes of violence against the self, presenting a theoretical framework for approaching DSBM as music which negotiates a complex economy of the staging and control of violence with respect to the self.

Keywords

suicide

depression

DSBM

extreme metal

violence

restriction

self-harm

nationalism

\section{Introduction}

In the underground subgenre of depressive suicidal black metal (DSBM), extremes of violence against the self are presented in combination with a restrictive version of black metal, itself an extreme form of metal music. Album covers frequently feature explicit and bloody photographs of self-cutting, or drawings of suicide by hanging. Band logos comprise heavily distorted lettering adorned with images of razor blades or nooses, or are 
made up of crude marks that resemble scars in skin. Vocals are tortured screams expressing extreme suffering, and guitar sounds are so distorted that they become an ambient atmospheric blur. Given the history of concern about metal and its health implications, I investigate DSBM as a case in which the representation of harm in music is overt, explicit and extreme, yet the health impact of the music is undetermined. Seeking to understand how specifically musical characteristics can connect with conceptual themes in music (rather than searching for meaning solely in lyrics, visual aesthetics, or subcultural and scenic forms of sociality, each often over-emphasized in analysis of popular music at the expense of focus on musical sounds), I discuss how different modalities of distortion and restriction may connect the sound of DSBM to themes of violence against the self. While gathering extensive evidence about health effects of DSBM on listeners is beyond the scope of this article, I hope to complicate overly simplistic depictions of harm and health in music, and indeed in understandings of 'self-harm' itself. As such, I present a theoretical framework for approaching DSBM as music which, in sound as well as in its surrounding aesthetics and discourse, negotiates a complex economy of the staging and control of violence with respect to the self.

\section{Approaches to suicide, self-harm and violence in relation to metal}

Connections between metal and violence have been the subject of long-running and often poorly evidenced popular and academic debates, with participation in metal music cultures often assumed to be linked with delinquency, depression, aggression, self-harm and suicide. Whether in behavioural psychology studies that assume a causal connection between metal and aggression (see Mast and McAndrew (2011) for a fairly recent example), or in sociological 'defences' of metal where music preference is read as a 
symptom of social alienation (e.g. Gaines 1998; Weinstein 1991), claims and counterclaims about this relation are made in the shadow of sensationalist media moral panic. Leaving aside the intricacies of these discourses and their claims which I attempt to address elsewhere (Coggins forthcoming 2019), here I wish instead to examine the specifically musical aspects of a metal subgenre, examining how in the case of DSBM, musical sound can relate to the strong themes of suicide, depression and self-injury that surround the music.

The challenge for musicology is to account for how musical sounds, timbres, styles, beats, the microscopic intricacies of distortion, rhythmic variation, vocal tone and so on, can connect to personal and social conditions, mediated identities, patterns of behaviour and real effects in the world. Any such analysis must also recognize the range and diversity of contingent examples, avoid making sweeping deterministic or essentialist claims, refuse to overclaim the significance of particular examples, evade mere overdescriptions of musical examples, and not assert unitary academically prescribed 'correct' interpretations and effects.

In this article I wish to explore how violence against the self is configured, represented, chosen or instantiated in sound, in connection with the wider aesthetic presentation of DSBM. The subgenre of DSBM is notable for its extreme and explicit representations of different kinds of violence in imagery and language, as well as having a recognizable and distinctive set of (sub)generic musical and sonic characteristics and conventions. I investigate the extreme sound and extreme iconography and themes of DSBM, suggesting that listening to this music forms a complex, multi-layered 
multimodal engagement with violence in abstraction, material sound, representation and affect.

\section{Rock ' $n$ ' roll suicides}

The idea of music provoking mental distress or causing problematic behaviour has a long history, with moral panics about mods and rockers (Cohen 1972), the glass harmonica causing hysteria and madness ( Spencer 2016), and racialized fears of the 'voodoo influence' of African American popular music leading white youth to deviance (Terry 1978) just a few examples which predate the existence of heavy metal music. Metal music, however, has often prompted extreme responses in relation to suicide, depression and violence, particularly in the wake of 1980s sensationalism in US news media and academic psychology.

As has been covered in detail elsewhere (Gaines 1998; Brown 2011), incidences of suicides of American teenagers in 1984 and 1985 occasioned two notorious court cases against Ozzy Osbourne and Judas Priest respectively, with parents convinced that specific metal songs or albums were to blame. The Osbourne song, 'Suicide Solution' (1980) was argued by the songwriter to be about the alcoholism-related death of AC/DC singer Bon Scott, and was protected by free speech laws, though Robert Walser has noted that the grim, despairing patterns of the music may undercut those cautionary lyrics (Walser 1993: 149). Judas Priest, meanwhile, were accused of inserting in their 1978 album Stained Class subliminal backwards verbal messages ('backmasking') that could incite suicidal action. Both cases were thrown out. Another metal suicide song became controversial for other reasons. Despite the music of Metallica's 'Fade to Black' (1984) 
reportedly 'actually forc[ing] the listener to witness the narrator's suicidal moment' (Pillsbury 2006: xxi) the song was criticized not for suicidal imagery, but by some fans for introducing acoustic guitars and a slow tempo to the band's hitherto aggressively fast thrash style (Pillsbury 2006: 55).

The imagery and practice of self-injury, especially cutting, have been present at least in fringes of rock and metal music since the late 1960s, again as a marker of extreme and transgressive behaviour. Iggy Pop, frontman of the Detroit punk rock group Stooges, was notorious for slashing his own chest with glass onstage (together with other wild acts) as early as the late 1960s (Rolling Stone 2016). Later rock musicians known for cutting themselves onstage include Nivek Ogre of Canadian industrial group Skinny Puppy in the 1980s, Trent Reznor of industrial metal group Nine Inch Nails, and Darby Crash of late 1970s LA punk band The Germs, who killed himself in 1980.

While suicide and other forms of transgressive violence may have been associated with metal and other heavy rock and punk music styles by the 1980 s due to moral panic coverage as well as the dark themes of some of the music and the excessive lifestyles of musicians, a new relation between metal and death was instantiated by the 1990 s second wave black metal. Notorious for church arsons beginning in summer 1992 and murders by Bård 'Faust' Eithun in August 1992 and most famously, of Øystein 'Euronymous' Aarseth by Kristian 'Varg' Vikernes in August 1993, it can be argued that the wave of violent actions associated with Norwegian black metal musicians was set off by the April 1991 suicide of Mayhem singer Per Ohlin, known as Dead. Notwithstanding Dead's depression, otherworldly fixations, and prior cutting of his arms onstage, his suicide and his bandmates' reactions can be seen as an escalation to further extreme action: the 
sardonic combination of his clothing (an 'I heart Transylvania' T-shirt) and suicide note ('Excuse the blood') as well as Euronymous's taking photographs of the scene, using them for the cover of live album Dawn of the Black Hearts (1995), and reportedly taking bone fragments as souvenirs. Lines from Dead's suicide note, together with lyrics enclosed in it about death, were used by Mayhem on their subsequent album De Mysteriis Dom Sathanas (1994). As well as escalating the seriousness of musicians' violent actions, this firmly valorized suicide as fulfilment of extreme ideology, and introduced visual depictions of suicide and its ambiguous celebration into the aesthetic of underground extreme metal. As Silk writes, with a certain mythologizing flourish, 'Black Metal was born in suicide' (2013: 5).

\section{From black metal and depression, suicide and self-injury, to}

\section{DSBM}

With suicide and self-injury established in black metal's repertoire of transgressive violence as early as 1991 , some bands began to make such themes more central to their aesthetic. Norwegian band Strid completed only three officially released songs, the single-track eleven-minute tape Strid in 1993, and a 7", also self-titled Strid, the following year. The length of the songs, their repetitive cyclical nature, slow pacing, simple 4/4 minor chord progression and sharply hissing distortion sound were influential in the style that became known as depressive black metal, together with the title of the tape hinting at suicidal themes. Bethlehem, from Germany, released demo tapes in 1992 and 1993 but became known for their second full album release in 1996, Te Dictius Necare (Latin for 'You must kill yourself'). Already distinctive for extreme subject matter of songs of mental illness and deprivation, the album became notorious for its 
strangled screams and wild vocal ranting. While generally faster and featuring more abrupt shifts than the mid-paced processions of most later DSBM, Bethlehem's tortured vocals and explicit reference to self-killing form an important influence for the subgenre.

While the Swedish band Shining are sometimes credited with instantiating DSBM, I would suggest that, with Strid and Bethlehem as well as Burzum's Hvis Lyset Tar Oss (1994) as key influences, it is the Australian one-man-band project Abyssic Hate that provides the first definite DSBM releases combining the signature monotonous, depressive sound with themes and explicit images of suicide, depression and self-harm. Perhaps less well-known because distant from the north European centre of extreme black metal, the band's first release had more ideological connotations of white nationalism than of self-harm in the title Cleansing of an Ancient Race and militaristic eagle with pentagram cover design (1994). Subsequent releases Depression (1995) and Life Is a Pain in the Neck (1996), both extremely limited tapes, were clearly themed around depression, suicide and self-injury with their artwork of grisly wrist and neck injuries, and song titles such as 'Suicidal Emotions', 'Depression', 'Despondency' and 'Endless Waves of Sadness'. Tracks extended beyond ten minutes and variations in chord progressions were restricted, producing a monotonous feel along with the slowish pace, trebly sound and levels of distortion tending towards indistinct droning hiss.

Further bands developed the sonic and aesthetic style in the later 1990s as black metal and its subvariations began to influence underground scenes across the world. In 2001, the band Silencer from Stockholm released their only full-length album Death Pierce Me, becoming somewhat notorious for the associated imagery and bizarre myths about the mental state and institutional history of singer Nattramn. Photographs of a 
bloody and heavily bandaged individual led to rumours that he had cut off his own hands and replaced them with pig's trotters. Other notable Swedish bands with longer recording careers include Shining and Hypothermia. The former band's (1998) debut EP Submit to Selfdestruction was adorned with drawings of hanged and bound bodies, and as Selim Yavuz reports is the first black metal recording to be explicitly described as 'suicidal black metal' (Yavuz 2015: 40). The band have gone on to release many more recordings coupled with monochrome images relating to self-harm and suicide, such as a heavily bleeding individual in a bathtub, and someone holding a gun in their mouth.

Hypothermia's releases have included several in the series Självdestruktivitet (selfdestructiveness $)(2004,2005)$, and Veins (2006), also with images of razor blades and scars.

In the United States, Leviathan and Xasthur were prominent examples of the style being taken up across the Atlantic, the trebly distortion, long monotonous songs, extreme screeching vocals were similarly married with verbal or visual references running from alienation to physical damage to the self. Other important DSBM bands outside the Nordic countries include Forgotten Tomb from Italy, Brazillian band Thy Light (whose logo includes symmetrical hangman nooses), Psychonaut 4 from Georgia in eastern Europe, Nocturnal Depression from France, and from Australia, Striborg and Woods of Desolation together with the latter's side project Forest Mysticism. In recent years, a large number of bands from all over the world have emerged, presenting a strictly defined musical, sonic, visual and verbal aesthetic that is readily identifiable as DSBM.

\section{Musical characteristics of DSBM: A subgenre of restriction}


Black metal since the 1990s has encapsulated a range of styles, from the raw, loose and more punk- (and Venom-) influenced metal as taken up by Darkthrone in some albums, to the more complex song structures of Emperor and Mayhem. DSBM by contrast is based on a severely restricted set of black metal's genre conventions. This strict sonic pattern is combined with images and themes that extend black metal's fascination with (and mythical origins in) extreme transgressive violence, in this case specifically violence against the self. The connection between the musicological characteristics of DSBM with its obsession with violence, suicide, self-injury and depression, I suggest, can be understood, in different abstract, representative and affective registers, as a staging of control and restriction in relation to marking of boundaries of the self.

Rhythm in DSBM is almost always mid-paced, largely in 4/4 or 6/8 time with guitar strumming tending to adhere to beats of the bar, often in slow picked arpeggios or in the classical black metal 'buzzpicking' or 'tremolo-picking' style, in which a busy, frenetic but also static, droning effect is produced by vigorous strumming on a constant chord, more or less strictly subdividing the beats of the bar. Drums are usually simple patterns without elaborate fills, with a kind of slack or 'leaning' syncopation. The sluggish rhythms and unhurried pace express a sense of despondency and lack of energy, despite fairly accurate commitment to a consistent beat, often throughout songs lasting from six to twenty minutes. Chord progressions are repeated in usually straightforward patterns of one chord strummed for one bar, changing chord when changing bar, and cycling through predictable and extensively repeated harmonic progressions without much variation. 
Vocals are contorted, indecipherable screams, placed lower in the mix than in some forms of metal, partly as the harsh and loud shrieking or screaming would be more overpowering than singing at the same levels. The screaming is sometimes further distorted with effects such as reverb, and is unlikely to follow melodic or rhythmic patterns of verse or chorus but instead interject at any point, with long pained howling or staccato screaming. Bodily sounds such as choking, vomiting, crying or coughing can often be heard (Yavuz 2015: 41). The vocal presentations, most commonly described as 'tortured', do not emphasize lyrical or verbal communication, instead using vocalizations which highly stress the vocal chords and which connote extremes of painful emotion.

This vocal style connects sonic distortion to cultural constructions of embodied pain and suffering, pushing human biological sound-making apparatus to extremes to sonically articulate emotional distress. Distortion in guitar sound is extremely important to DSBM. While there may be acoustic or 'clean' picked guitar arpeggio parts, the distorted, slow to mid-paced tremolo riffing on simple chord progressions is fundamental to DSBM, even more so than in black metal which tends to feature more variation. In DSBM, the combination of heavily distorted guitars with tremolo playing style and production which emphasizes treble registers, sometimes together with frequent crash cymbals, leads to an overall sonic effect of hissing, high-pitched droning. Since sonic heaviness in metal and other popular musics often revolves around bass (Henriques 2011), with the word 'heavy' itself suggesting mass and therefore loud, low noises (Mynett 2016), the high register emphasis in DSBM could imply a certain weightlessness, despite the emotional connotations of extremely distressing emotions and physical pain. 
DSBM thus presents both a restriction and an extension of the characteristics of second wave black metal, with variation reduced but established musical patterns extended to further extremes and associated with more extreme physical and conceptual imagery. This combination of restriction and extension is true also of the imagery of suicide and self-injury: present in part in earlier black metal but in DSBM refined to a fairly limited convention of misty forests, empty landscapes, images of cutting or suicide by hanging. While song titles, band names and images may clearly indicate a concern with suicide, self-injury and depression, the musical characteristics also model such states of mind and actions. For Dominic Fox, the music of Xasthur, 'monotonous, endlessly circling around the same motifs', reflects the same impulses in depressive thinking, and while it appears as 'a kind of psychical assault, an attempt to disorientate and demoralise the listener, it is also strangely tranquil, almost comforting, in its sonic textures' (Fox 2009: 48-49).

\section{Criticism returning to restriction and distortion}

There has been some resistance to DSBM from black metal listeners, despite DSBM's sound often obsessively conservative in reproducing the style of some of the most

canonical 1990s black metal (such as that of Darkthrone's Transilvanian Hunger (1994) and Burzum's early style). DSBM is in some ways an ultra-orthodox version of black metal, while somewhat paradoxically also proving transgressive for overly focussing on some of the most sensitively transgressive themes of black metal, such as mental fragility and depression, in contrast to a self-proclaimed Nietzschean, social Darwinist elitist current in some black metal ideology. However, as Dayal Patterson notes, that while DSBM may be 
regarded by some as being problematic on ideological grounds, the argument being that black metal should be about strength and something approaching a warrior spirit, as opposed to weakness, vulnerability and self-suffering, $[\ldots]$ it should be remembered that madness, depression and mental fragility have been a subject of black metal lyrics since the early days of the genre.

(Patterson 2015: 40)

Criticism has also come from prominent DSBM musicians themselves. 'Herr Morbid' from Forgotten Tomb outlines his opinion of how DSBM has developed: the main concept has been completely distorted by all the bands that followed [...] these new bands think that you can record at home with a drum-machine and some software, playing a single arpeggio in A-minor for ten minutes and that's being depressive. What the fuck is wrong with these people?

(Herr Morbid quoted in Patterson 2015: 270)

Wiederganger from the band Total Negation expresses similar contempt:

The problem is that it is 'easy' to play depressive black metal, or at least you can get away with doing almost nothing or using very little effort. Just loop a slow half-time drumbeat, play a minor chord arpeggio on the guitar, and lay some 'tortured reverb vocals' on top of it. Here we go, next DSBM album. Maybe that's exactly how I started, but its definitely not how I continued.

(Wiederganger quoted in Patterson 2015: 290)

While such elitist posturing is a familiar element of black metal's rhetoric of personal sovereignty, the musicians identify clear patterns in their own music and in the 'other' DSBM judged to be inferior. In addition, given the emphasis in DSBM on distortion, extension and repetition of black metal's sonic tropes, it is ironic that musicians are literally complaining about distortion of the concept and the repetition of a template. 
In a further point of tension, opposing views on suicide can be found from DSBM musicians. The band Forgotten Tomb state that their music has failed if it is received as therapeutic, apparently actively wishing their listeners to kill themselves (Patterson 2015): 70). Meanwhile Psychonaut 4 have posted online that they 'sincerely wish, that in the next year you will stop listening to us at some point, just because you will not need our music anymore' (quoted in DePasquale 2018). By black metal's standards, Psychonaut 4's position could be argued to be more extreme in its adoption of a reflective empathy, with Forgotten Tomb's confrontational posture of indifferent individualism is highly conventional. Nevertheless, in both cases the relation between a listener and DSBM tends towards its own demise, in a further abstraction of an unstable self-ending impulse despite the sustained depressive monotony of the sound.

\section{Distortions and restrictions: Staging violence against the self in}

\section{different registers}

The same sonic qualities, though perhaps to a lesser degree and with more variation, are often described as depressive black metal, with DSBM requiring a deeper commitment to extreme and restricted instantiations of these musical elements, together with explicit visual and/or verbal references to suicide, self-injury or depression. It appears that in the context of describing black metal, 'depressive' can often function as a subgeneric musical descriptor, with 'suicidal' additionally referring to a visual or verbal component. Yet while depression and suicide are important themes named in the subgenre designation, self-injury and specifically cutting is an equally important element in DSBM aesthetics. Further suggesting that in fact self-cutting is the more central foundation of DSBM than either depression or suicide, each of the important generic elements of DSBM as 
described earlier can be understood as a staging of distortion or restriction as a cut against the self.

While self-cutting is sometimes mistakenly equated with suicidal behaviour, other sources consider this kind of action (whether described as self-injury, self-mutilation or self-harm) as importantly different from suicide (Fox and Hawton 2004: 14). Some authors and clinical practitioners suggest that, rather than simply predicting or implying suicidal thoughts, actions such as cutting, hitting one's head or burning skin may be impulses that divert suicidal thoughts in a positive and life-affirming, if desperate and dangerous, attempt to control challenging mental health issues (Favazza 2011: 71). Selfcutting offers calming effects, relaxation and even a trance effect which can numb mental pain (Levenkron 1998: 24-27). It can be a way of paradoxically finding power in one's body through exerting power over one's body (in the context of feeling disempowered in other aspects of life), not in a failed pursuit of death but a defiance of death (Joffe 1995: 56; Nasser 2004: 19). Cutting and scarification can occur within a range of practices such as tattooing, piercing and circumcision, practices in which identity, community, ritual and health might be constructed (Favazza 2011: 200). Established practices of western medicine such as surgery and anaesthetic or inoculation injections involve cutting or penetrating the body for health purposes (Nasser 2004: 20), though their institutionalized and socially accepted forms lead us to group them significantly differently to other ways of modifying the body and piercing its boundaries. Compelling attempts have been made to understand even suicide as a move towards control: 'like any other symptom, it has a regulating function as well, and at times even a stabilising one, strange as this may sound' (Kind 1999: 10), indicating the difficulties and paradoxes of conceptualizing 
suicide as something an agent can desire for themselves, which will end that agent and their desires. Cuts against the self therefore, are interventions in an economy of power and control, forming coherent if extreme attempts to stage control over pain, violence and suffering.

If this is so, then clearly the repetition of cutting imagery in DSBM references such a mechanism. Other aspects of DSBM can also represent the staging of similar economies of restriction and damage, involving violence but representing attempts to symbolically manage it. Screaming is an example of this, where emotional pain is understood to prompt such vocal sounds. The staging of a relation between self and world in the voice has been explored by David Burrows in Sound, Speech and Music (1990), in which he argues that human vocalisations model such a relationship. Voice is produced by the cutting of the vocal chords into a column of expressed air in order to make sound. For Burrows, the airflow represents the individual self, while the encroachment of the parts of the throat that make sound represents the impact of external psychological, social or practical forces. Here then, in the voice,

self and other are represented in the encounter between exhalation and the tightened vocal fold and in this way brought symbolically under the vocalizer's control.

$$
\text { (Burrows 1990: 64) }
$$

While self and other are modelled in the breath and the vocal chords, both are controlled by the self and therefore represent a gesture where the self communicates its own interpretation of and emotional response to this relationship. As David Graeber has noted, this bears some relation to Freud's depiction of childhood games as ways of re-staging troubling aspects of their experience of the world, in safe ways that bring all aspects of such dynamics within the child's control (Graebner 1987; Freud [1920] 2015). The key 
example here is the game of repeatedly hiding and finding a doll, thereby mediating anxiety about the mother leaving through bringing the power of loss and retrieval under the child's control.

In DSBM the extreme vocalisations closely relate to the cuts into the body depicted on album covers, with the vocal fold cutting dramatically into the breath of the singer. While in theorizing pain, Elaine Scarry might overstate its incommunicability, she is right to highlight the importance of non-linguistic uses of the voice in signalling suffering:

To witness the moment when pain causes a reversion to the pre-language of cries and groans is to witness the destruction of language.

(Scarry 1985: 6)

In some cases, musicians report cutting themselves onstage or in recording studios in order to ensure a close connection between the recorded sounds of the body in pain. Often the DSBM vocal scream is highly restricted, even strangled. Following Burrows, this harsh restriction of the vocal fold to produce a scream can represent the self, modelling incredible pressures on the imagined self.

Distortion can also be thought of as a similar modelling of relationship between self and other, between signal and channel, between the body and a cutting into the body at its limits. Sheila Whitely has usefully considered a similar relationship in the music of Jimi Hendrix, perhaps the most important experimenter with distortion in popular music history. Noting that in 'Purple Haze' the levels of distortion are such that the pitch can sometimes be difficult to hear, Whiteley suggests that if pitched notes stand for personal consciousness and distortion as a kind of self-effacing violence, then 'the sheer volume of noise works towards the drowning of personal consciousness' (Whiteley 2000: 241-43). 
Distorted electric guitars also signify damage in a historical context, with the first such effects coming from damaged speaker cones in amplifiers, players later seeking those sounds by deliberately slashing cones and eventually having distortion effects built in to their equipment. Also noting a sense of absorption deriving from distortion and repetition, Whiteley's analysis focuses on the music's modelling of a psychedelic consciousness that appears quite different from depression (noting, e.g., the 'upward movement' that characterizes the trip in sound and mind, which in DSBM would be replaced with a despondent monotony) (2000: 236). However, both depression and psychedelia are arguably both non-standard modes, with trance and altered states also evident in reports of self-harm (Levenkron 1998: 28).

In DSBM's visual aesthetic as well as the depicted content, there is distortion, restriction and repetition. From black metal's already firmly established conventions, DSBM albums display a restricted set, with forest scenes almost the only pictures other than ones which explicitly show cuts to the body; as in sound, DSBM's aesthetic restrictively cuts into the possibilities afforded by black metal's genre expectations. Parameters for colour and design are also restricted, with monochrome design overwhelmingly preferred. The stark, high-contrast 'photocopy' aesthetic of much underground black metal visual design can still be found in DSBM, though there is a higher prevalence of misty, low-contrast, grey images. Typographically, DSBM continues black metal's preference for fraktur or blackletter fonts, a form of visual distortion of lettering (Coggins 2018: 129-36), while band logos are often even more indecipherable than black metal examples generally. 
By showing how distortion and restriction are modelled in DSBM's sound and aesthetics, with reference to clinical literature which suggests that engaging with models rather than explicit practices of violence against the self may assist in averting rather than promoting suicide, this analysis complicates simplistic notions of causation. The 'hypodermic' model of musical influence was criticized by Walser (1993: 141), however it should also be acknowledged, with Titus Hjelm, that we must still account for music having effects on people in harmful and helpful ways (Hjelm 2015). Leaving aside the absurd (though shockingly influential) moral panic accusations that music 'about' suicide or that depicts self-harm or violence must therefore cause it, instead we can consider a complex mechanism of staging in the music, and in its use or reception by listeners. The relationship between the self and the world, or perhaps between the imagined inner self and the violent, painful demands on it in psychic, material, physical and social spheres, are modelled in DSBM by staged relationships in different registers between notes and distortion; between breath and scream (figured also in the depictions of constricted throats and nooses); between ideas of the body and cuts against the body; between legible text and distortion in blackletter typography or opaque logo design; between black metal and the restricted set of DSBM's musical conventions.

\section{Purification and violent demarcation of boundaries: Connections}

\section{with nationalism}

Associations with extreme political ideologies in black metal have existed alongside the genre's notoriety regarding violence since the 1990s where Euronymous, for example, professed interest in communism as well as fascism in the pursuit of extreme connotations. Increasingly over the decades of black metal's global expansion, concern 
has developed over far right and fascist symbols and ideas, either overtly in the marginal NSBM (National Socialist black metal) scene, or more commonly, in ambivalent guise in more mainstream black metal bands. Controversies have erupted over bands using sunwheel symbols (as used by the Nazi SS), tattoos resembling swastikas, prejudicial slogans and other arrays of images vaguely but rarely definitively connoting extreme nationalism or white supremacy.

This may seem an issue at some remove from the questions of self-harm and suicide in DSBM, and the genre has not attracted huge controversy (perhaps surprisingly with its highly explicit imagery) likely due to its low profile even within extreme metal. One exception is Shining, perhaps the best known DSBM band, whose confrontational on- and offstage persona seems to court controversy deliberately. Another exception is the one-man band Abyssic Hate, whose influential early recordings I consider to be the earliest examples encapsulating all elements of DSBM, and consistently so over several releases. Before images of scarred bodies on albums such as Suicidal Emotions (2000), though, Abyssic Hate's first release was titled Cleansing of an Ancient Race (1994), including with some early copies a metal Australia-shaped pendant inscribed with the slogans 'Australia for Australians' and 'White Australia', with the cover displaying a design of an eagle clutching an inverted pentagram, resembling a military-style crest. While the overt themes of later releases were largely confined to suicide, depression and self-harm, given that these early elements strongly suggest white nationalism and even genocide, occasional later references such as contributing the same tracks from Cleansing of an Ancient Race to a split release entitled United by Heathen Blood, recording a song called 'The Blood War', and dedicating Suicidal Emotions to black metal musician, right- 
wing extremist and convicted murderer Henrik Möbus ensure that this association with extreme racist nationalism must be viewed as a sustained interest or commitment in this particular band's output.

While even ambivalent or plausibly deniable symbols connoting fascism or racism are quite rare in DSBM, the presence of some overt examples is important to discuss. As I have suggested in writing about nationalism in 1990s Nordic black metal, whether founded in 'whiteness', North European identity, with associations of Germanic paganism or along the lines of existing nation states, a key psychological concern appears to be related to purification and a will to power (Coggins 2014). A contradictory tension is produced, between on one hand, black metal's imagining of a nation, and on the other, its elitist misanthropic individualism (Olson 2008: 4). This tension appears elsewhere in extreme right circles, where

paradoxically, then, cantankerous individuals who are hardly capable of cooperation, much less of taking orders, populate a milieu that stresses an organic view of race and holds as ideal an authoritarian collectivism.

(Gardell 2003: 70-71)

In imagining a purifying radical violence against those who do not belong to the nation, the impulse to radicalisation leads to ever-more stringent criteria of acceptability, until the population of any black metal nation is inevitably reduced to one. Violent purging does not stop at the boundaries of the individual, the self must be rid of unworthy characteristics and affectations. National or group solidarity is suggested or reinforced through bodily metaphors casting the nation as an individual organism.

(Coggins 2014: 481)

Here a connection with DSBM's self-harm imagery becomes clear, or perhaps DSBM becomes a further, yet more extreme version of the aggressive infliction of restrictive 
violence into the nation of one, a cut into the body of the individual. Jenna DePasquale, observes this connection, contrasting nationalist currents in black metal with violence in DSBM, in which

appeals to external natural realms are not asserting a need to regain the alleged purity of Europe, but rather, to mourn a strained relationship between soul and society. An enemy takes form not in one people or race, but mainly, the self (and perhaps the occasional neurotypical). And so, as the years have passed, the knife was struck inward and slowly turned.

(DePasquale 2018)

\section{Collapsing paradoxes of distortion}

Self-injury and even suicide contain or articulate paradoxes. Sufferers suggest that selfharm involves using pain to dispel pain ('Juanita' quoted in Levenkron 1998: 39), functioning as both punishment and salvation, and provoking both pride and shame ('M.M.' 2004: x). Therapists also observe that self-harm attacks the body yet seeks identity founded in the body (Nasser 2004: 19), with the effect of cutting a paradoxical 'counterpleasure' according to Glucklich (2001: 17). Suicide too is a violent attempt at regulating violence (Kind 1999: 10), and suicide aims at restoring or improving a relation between the self and another despite the obvious contradiction that it will inevitably end that relation and all others for the self (Kind 1999: 10).

Such paradoxes are articulated in the distortion in DSBM that tends towards its own collapse, producing contradiction, paradox or fragile balance between sense and chaos. Inner tensions are already rooted in black metal: the primitivist critique of modernity in music absolutely defined by its use of modern electrical equipment; the 'tension around kvltness and authenticity [as] a result of the fact that kvltness is a 
commercial force, even if it pretends otherwise' (Hagen 2014: 234); in the odd

perceptual effects of tremolo-picking (Kahn-Harris 2007: 33); and, I will suggest, fundamentally in its relationship with distortion. In this regard, distortion as a fundamental characteristic of metal music is a productive area in which to consider such paradoxical dynamics in sound and how it connects to aesthetics, culture, language and ideology.

In extreme sound and extreme adherence to certain black metal conventions, DSBM veers particularly close to the collapsing paradoxes of distortion. For many black metal listeners, DSBM is unacceptable as black metal despite clearly (over)identifying as such; this simply shows the narrowness of boundaries between embodying extremes of black metal ideology and the complete dissipation of this intensity. Paradoxes of transgression and paradoxes of distortion appear in a number of ways in DSBM, with their unstable dynamics related to the instability of spectacular 'transgressive subcultural capital' as identified by Keith Kahn-Harris in metal scenes in dialectic combination with the archiving work of 'mundane' subcultural capital (Kahn-Harris 2011).

There is in distortion already a sense of the impossible or ineffable, given that it is literally the sound of limits being exceeded.

The input signal from the guitar is greatly amplified to push the signal level above the supply voltage. As this is not possible, the signal becomes saturated at the supply voltage level.

(Whiteley 2000: 260)

This dynamic evokes depictions of mystical discourse, as attempting to say the unsayable, experimenting at the edges of a language or symbolic tradition to investigate the limits of what can be said (Coggins 2017). References to mysticism and marginal 
religious practices are not uncommon in relation to self-cutting in DSBM, and in wider literature on self-harm and suicide (e.g. Levenkron 1998: 20). Meanwhile, extremes of asceticism, eating disorders and torture are often encountered in close proximity to discourses of sacrifice, ritual and religion (Glucklich 2001). As part of this paradoxical and impossible communication, distortion emphasizes the materiality of signs, the thingness of a medium and the edges of communication channels. This connection to physicality is noted by Alexander Reed in discussing industrial music and the body (a genre also known for some musicians' onstage cutting and explorations of violence, such as in Nine Inch Nails and Skinny Puppy).

Metaphorically speaking, this music forces open the body, exceeding the capacity of flesh to contain itself. This is also the musical impact of distortion, in which a sound's amplitude exceeds its medium's capacity to contain it.

(Reed 2013: 291)

However, excess distortion undermines itself. Mark Mynett has conceptualized this in the sphere of contemporary metal music production, in an article entitled 'The Distortion Paradox'. Mynett notes that distortion is fundamental to metal sound across all metal genres (though DSBM has very different production values to the styles that he discusses). The article demonstrates that while distortion is key to the sound and energy of metal, excesses of distortion disguise pitch, which 'results in the listener's ability to perceive the energy and intensity involved becoming obscured or lost' (Mynett 2016: 77, 81). Generally, the more distortion there is in a metal guitar part, the more desirable and exciting it is within a metal paradigm. But crucially, this is only true up to a point, and distorting further after this point will actually lead to less sonic energy. In some DSBM recordings, levels of distortion certainly go beyond the limit that Mynett suggests would 
make music less heavy, as distinction is lost in a droning blur. In much DSBM, the extreme levels of distortion can even lead to a smoothing out of rough timbres, as notes become blurred in much the same way as tremolo-picking obscures individual strums. This leads DSBM in some cases to sound more like ambient humming than the fiercely distorted, aggressively strummed black metal that it is, especially in combination with the stately pace and slow, predictable chord progressions that most DSBM follows. Further compacting this indistinction and showing that it lack of distinction is actually desirable in underground DSBM is the preference for the cassette tape, decried in much popular music as an anachronistic format due to its poor sound quality. However, the specifics of this 'poor quality' - the fact that instruments are less distinguishable, and that the reproduction becomes murkier over time as the medium degrades - are in fact an ideal fit for depressive black metal and its sonic and bodily fascination with transgressing boundaries in violence and distortion.

\section{Conclusion}

While depression and suicide are prominent in the name of DSBM, it is evident from the range of imagery used that self-injury, specifically cutting, is also a crucial theme in understanding the subgenre. While undoubtedly connected, depression, suicide and selfinjury are distinct, with self-injury and suicide sometimes best understood as opposing impulses; that is, that self-injury may be enacted in an attempt to ward off suicidal thoughts or to channel away and therefore recover from depressive episodes. This violent attempt to deal with the effects of violence, the cut against the self to try and heal the self, I have suggested, is a dynamic which is enacted at several levels in DSBM, from the musical to the thematic. Distortion in guitar sound models a cut against the self and 
thereby an enhanced consciousness of the limits of the musical self as figured in melody; screams themselves model an extreme relation with external pressures and stresses, as is further underscored by the imagery of nooses and pressure on the neck; severe restrictions are cut into the range of possible musical elements within the conventions of black metal. This article has attempted to show how sound and musical structures, within an established extreme metal subgenre paradigm, might connect in close structural relationships with the conceptual themes present in the subgenre. Yet beyond how distortion and violence against the self are figured in the music itself and its surrounding themes and aesthetics, the relationship with listeners in reception adds a further dimension in which the complex staging of violence in relation to the self may be enacted.

Several listeners suggest that a motivation for listening to DSBM is that it is comforting to know that others feel like them. This feeling of commonality between the listener's sense of their own mental distress and their reception of another's suffering cannot be accounted for in simply the lyrical, vocal or visual presentations of suffering, but are also I suggest connected to the sound presented by the modelling of self and other that takes place in extreme distortion. In a forum thread on Reddit.com, a user asks 'does anyone else find dsbm to help with depression?', elaborating his question and then receiving a range of responses (spelling and grammar preserved from original):

I'm sure some of you get where I'm coming from. Whenever I listen to dsbm, it kind of reminds me that depression is something other people go through as well. I in a way feel not alone. I also feel like it helps me with actually confronting the emotions. Im totally agree with you. For me dsbm is a way to express, in a more conceptual form, my feels. This music dont depress me more of that $\mathrm{i}$ already am, on the contrary it makes 
me feel better because give me a way to release all this shit. Sorry for my english, I wish I could express myself better.

Dsbm makes it worse for me.. I start to think about depressed people and why we are so fucked up. Why do we feel this way and why the pain won't stop?

Yeah, I'd say dsbm as a whole has helped me deal with my depression. Got me into playing and learning guitar and stuff. At the same time though, if I'm really, really bad it usually doesnt help to listen to it.

(thread in Reddit.com, Joey2213 2017)

Having examined the ways in which violence against the self is depicted or enacted within DSBM, a further question concerns the effects on listeners who accept this package of multi-layered staging of violence and restriction and use it in their own contexts. While even listening to metal may have been interpreted as a form of self-harm in itself by some under the influence of moral panic sensationalism, it is nevertheless the case that listening to DSBM does operate within a network of relations which concerns experiencing the presentation of different forms of violence against the self. Even selfharm in the form of cutting, and even suicide, according to the clinical therapy literature, should not be understood as straightforwardly harmful, but as action performed by agents in response to harm, which may in fact also cause harm in quite extreme ways, but are at least in part followed in order to minimize harm.

\section{References}

Abyssic Hate (1994), Cleansing of an Ancient Race, Cassette, Melbourne: Self-released.

— (1995), Depression, Cassette, Melbourne: Self-released.

- (1996), Life Is a Pain in the Neck, Cassette, Melbourne: Self-released. (2000), Suicidal Emotions, Cassette, Mügeln: No Colours Records. 
Abyssic Hate/Det Hedenske Folk (1997), United by Heathen Blood, Cassette, Melbourne: Bloodless Creations.

Bethlehem (1992), Bethlehem, Cassette, Grevenbroich: Self-released.

— (1993), Promo March '93, Cassette, Grevenbroich: Self-released.

_ (1996), Dictius Te Necare, Compact Disc, Winter Springs: Red Stream.

Brown, A. (2011), 'Suicide solutions? Or, how the emo class of 2008 were able to contest their media demonization, whereas the headbangers, burnouts or "Children of Zoso" generation were not', Popular Music History, 6:1\&2, pp. 19-37.

Burrows, D. (1990), Sound, Speech and Music, Amherst, MA: University of Massachusetts Press.

Burzum (1994), Hvis Lyset Tar Oss, Compact Disc, Hadleigh: Misanthropy Records. Coggins, O. (2014), 'Nationalist black metal, black metal nation’, in G. Narayan Ray, J. Sarkar and A. Bhattacharya (eds), Writing Difference: Literature, Identity and Nationalism, London: Atlantic, pp. 460-81.

(2017), 'Unstable metaphors for the inaccessible: Mysticism, blackletter, drone metal', in J. Harris and O. Coggins (eds), Sustain//Decay: A Philosophical Exploration of Drone Music and Mysticism, St Louis, MO: Void Front Press, pp. $15-27$.

(2018), Mysticism, Ritual and Religion in Drone Metal, London: Bloomsbury Academic.

— (forthcoming 2019), 'Imaginaries of spirituality, violence and health impacts in metal music: A critical history and case study', Approaches: An Interdisciplinary Journal of Music Therapy, 11:1. 
Cohen, S. (1972), Folk Devils and Moral Panics: The Creation of the Mods and Rockers, New York: HarperCollins.

Darkthrone (1994), Transilvanian Hunger, Compact Disc, Dewsbury: Peaceville.

DePasquale, J. (2018), ‘A fly over the fringes: Depressive suicidal black metal, past, present, and beyond', InvisibleOranges.com, 26 July, www.invisibleoranges.com/depressive-black-metal/. Accessed 7 October 2018.

Favazza, A. (2011), Bodies under Siege: Self-Mutilation, Nonsuicidal Self-Injury, and Body Modification in Culture and Psychiatry, 3rd ed., Baltimore, MD: Johns Hopkins University Press.

Fox, C. and Hawton, K. (2004), Deliberate Self-Harm in Adolescence, London and Philadelphia, PA: Jessica Kingsley.

Fox, D. (2009), Cold World: The Aesthetics of Dejection and the Politics of Militant Dysphoria, Winchester and Washington: Zero Books.

Freud, S. ([1920] 2015), Beyond the Pleasure Principle (trans. J. Strachey), London: Dover Publications.

Gaines, D. (1998), Teenage Wasteland: Suburbia's Dead End Kids, Chicago, IL and London: University of Chicago Press.

Gardell, M. (2003), Gods of the Blood: The Pagan Revival and White Separatism, Durham, NC and London: Duke University Press.

Glucklich, A. (2001), Sacred Pain: Hurting the Body for the Sake of the Soul, Oxford: Oxford University Press. 
Graebner, E. (1987), 'Review. The musical mind: The cognitive psychology of music by John A. Sloboda and music and the emotions: The philosophical theories by Malcolm Budd', Music Analysis, 6:1\&2, pp. 179-92.

Hagen, R. (2014), 'Kvlter than thou: Power, suspicion and nostalgia in black metal fandom', in L. Duits, K. Zwaan and S. Reijnders (eds), The Ashgate Companion to Fan Cultures, Farnham: Ashgate, pp. 223-36.

Henriques, J. (2011), Sonic Bodies: Reggae Sound Systems, Performance Techniques, and Ways of Knowing, London: Continuum.

Hjelm, T. (2015), 'Controversial metal and controversial religion: Theorising the connections', in T.-M. Karjalainen and K. Kärki (eds), Modern Heavy Metal: Markets, Practices and Cultures, Helsinki: Aalto University, pp. 494-502.

Hypothermia (2004), Självdestruktivitet Född Av Monotona Tankegångar, Cassette, San José: Meutre Noir Records.

— (2005), Självdestruktivitet Född Av Monotona Tankegångar II - Monoton Negativitet, Cassette, San José: Meutre Noir Records.

- (2006), Veins, Compact Disc, Stockholm: Insikt.

Joey2213 (2017), 'Does anyone else find dsbm...', thread in Reddit.com, 11 September, www.reddit.com/r/dsbm/comments/6zekyo/does_anyone_else_find_dsbm_to_hel p_with_depression/. Accessed 7 October 2018.

Joffe, Rosalie (1995), “'Don’t help me!” - The suicidal adolescent’, in M. Laufer (ed.), The Suicidal Adolescent, London: Karnac Books, pp. 53-68.

Judas Priest (1978), Stained Class, Vinyl LP, New York: Columbia Records. 
Kahn-Harris, K. (2007), Extreme Metal: Music and Culture on the Edge, Oxford and New York: Berg.

- (2011), “YYou are from Israel and that is enough to hate you forever": Racism, globalization, and play within the global extreme metal scene', in J. Wallach, $\mathbf{H}$. Berger and P. D. Greene (eds), Metal Rules the Globe: Heavy Metal Music around the World, Durham, NC and London: Duke University Press, pp. 200-26.

Kind, J. (1999), Suicidal Behaviour: The Search for Psychic Economy (trans. P. Foulkes), London and Philadelphia, PA: Jessica Kingsley Publishers.

Levenkron, S. (1998), Cutting: Understanding and Overcoming Self-Mutilation, London and New York: W.W. Norton.

Mast, J. F. and McAndrew, F. T. (2011), 'Violent lyrics in heavy metal music can increase aggression in males', North American Journal of Psychology, 13:1, pp. $63-64$.

Mayhem (1994), De Mysteriis Dom Sathanas, Compact Disc, Oslo: Deathlike Silence. _ (1995), Dawn of the Black Hearts, Vinyl LP, Medellin: Warmaster Records.

Metallica (1984), 'Fade to Black', Ride the Lightning, Vinyl LP, Philadelphia: Megaforce Records.

'M.M.' (2004), 'Inside my wounds', in J. L. Levitt, R. A. Sansone and L. Cohn (eds), Self-Harm Behaviour and Eating Disorders: Dynamics, Assessment, and Treatment, New York and Hove: Brunner-Routledge, pp. ix-xii.

Mynett, M. (2016), ‘The distortion paradox: Analyzing contemporary metal production’, in A. R. Brown, K. Spracklen, K. Kahn-Harris and N. W. R. Scott (eds), Global 
Metal Music and Culture: Current Directions in Metal Studies, New York and London: Routledge, pp. 68-88.

Nasser, M. (2004), 'Dying to live: Eating disorders and self-harm behaviour in cultural context', in J. L. Levitt, R. A. Sansone and L. Cohn (eds), Self-Harm Behaviour and Eating Disorders: Dynamics, Assessment, and Treatment, New York and Hove: Brunner-Routledge, pp. 15-30.

Olson, B. H. (2008), 'I am the black wizards: Multiplicity, mysticism and identity in black metal music and culture', unpublished MA dissertation, Bowling Green: Bowling Green State University.

Ozzy Osbourne (1980), ‘Suicide Solution’, Blizzard of Ozz, Vinyl LP, London: Jet Records.

Patterson, D. (2015), Black Metal: The Cult Never Dies Volume One, London: Cult Never Dies.

Pillsbury, G. T. (2006), Damage Incorporated: Metallica and the Production of Musical Identity, London: Taylor \& Francis.

Reed, A. (2013), Assimilate: A Critical History of Industrial Music, Oxford: Oxford University Press.

Rolling Stone (2016), ‘20 wildest Iggy Pop moments’, Rolling Stone, 21 April, Www.rollingstone.com/music/music-lists/20-wildest-iggy-pop-moments72545/first-eyewitness-account-of-iggy-slicing-up-his-torso-may-23-196924964/. Accessed 7 October 2018.

Scarry, E. (1985), The Body in Pain: The Making and Unmaking of the World, New York and Oxford: Oxford University Press. 
Shining (1998), Submit to Selfdestruction, 7" Vinyl EP, Halmstad: Selbstmord Services.

Silencer (2001), Death Pierce Me, Compact Disc, Zeltingen-Rachtig: Prophecy

Productions.

Silk, J. (2013), ‘Open a vein: Suicidal black metal and enlightenment', in A. Ishmael, Z.

Price, A. Stephanou and B. Woodard (eds), Helvete: A Journal of Black Metal

Theory 1, New York: Punctum Books, pp. 5-20.

Spencer, M. (2016), 'The glass harmonica: The world's most dangerous instrument?',

Royal Opera House Online, 25 April, www.roh.org.uk/news/the-glass-harmonica-

the-worlds-most-dangerous-instrument. Accessed 7 October 2018.

Strid (1993), Strid, Cassette, Askim: Self-released.

_ (1994), Strid, 7”Vinyl EP, Tübingen: Malicious Records.

Terry, R. R. (1978), Voodooism in Music and Other Essays, Stratford, NH: Ayer Co Publishing.

Walser, R. (1993), Running with the Devil: Power, Gender and Madness in Heavy Metal Music, Hanover, NH: University Press of New England.

Weinstein, D. (1991), Heavy Metal: The Music and Its Culture, New York: Da Capo Press.

Whiteley, S. (2000), 'Progressive rock and psychedelic coding in the work of Jimi Hendrix', in R. Middleton (ed.), Reading Pop: Approaches to Textual Analysis in Music, Oxford and New York: Oxford University Press, pp. 235-61.

Yavuz, M. S. (2015), 'Dead is dead: Perspectives on the meaning of death in depressive suicidal black metal music through musical representations', unpublished MA thesis, London: Royal Holloway, University of London. 
Owen Coggins has asserted his right under the Copyright, Designs and Patents Act, 1988, to be identified as the author of this work in the format that was submitted to Intellect Ltd. 